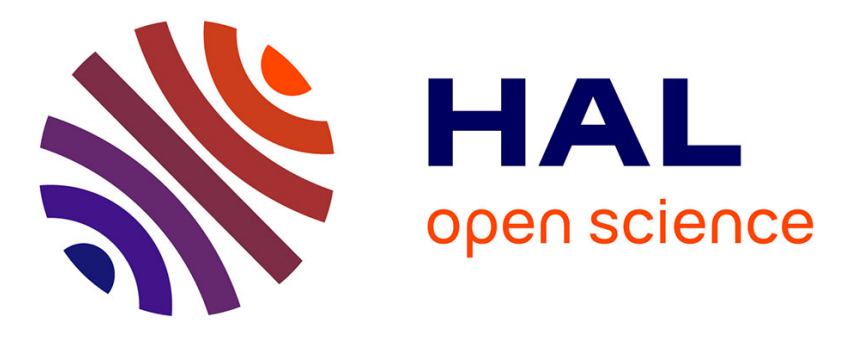

\title{
High prevalence of mutations in perilipin 1 in patients with precocious acute coronary syndrome
}

Nathalie Bonello-Palot, Marc Laine, Thomas Cuisset, Thibault Ronchard, Camille Desgrouas, Françoise Merono, Manal Ibrahim-Kosta, Mathieu Cerino, Arnaud Blanchard, Patrice Bourgeois, et al.

\section{To cite this version:}

Nathalie Bonello-Palot, Marc Laine, Thomas Cuisset, Thibault Ronchard, Camille Desgrouas, et al.. High prevalence of mutations in perilipin 1 in patients with precocious acute coronary syndrome. Atherosclerosis, 2020, 293, pp.86 - 91. 10.1016/j.atherosclerosis.2019.12.002 . hal-02624173

\section{HAL Id: hal-02624173 \\ https://hal.inrae.fr/hal-02624173}

Submitted on 28 Apr 2021

HAL is a multi-disciplinary open access archive for the deposit and dissemination of scientific research documents, whether they are published or not. The documents may come from teaching and research institutions in France or abroad, or from public or private research centers.
L'archive ouverte pluridisciplinaire HAL, est destinée au dépôt et à la diffusion de documents scientifiques de niveau recherche, publiés ou non, émanant des établissements d'enseignement et de recherche français ou étrangers, des laboratoires publics ou privés. 
High prevalence of mutations in Perilipin 1 in patients with precocious acute coronary syndrome

Nathalie Bonello-Palot ${ }^{1,2}$, Marc Laine ${ }^{3}$, Thomas Cuisset ${ }^{4,5}$, Thibault Ronchard ${ }^{3}$, Camille Desgrouas $^{1,6}$, Françoise Merono ${ }^{1}$, Manal Ibrahim-Kosta ${ }^{5}$, Mathieu Cerino ${ }^{1,2}$, Arnaud Blanchard $^{1}$, Patrice Bourgeois ${ }^{1,2}$, Nicolas Levy ${ }^{1,2}$, Anderson Loundou ${ }^{6}$, Pierre-Emmanuel Morange $^{5,7,8}$, Marie-Christine Alessi ${ }^{5,7}$, Catherine Badens ${ }^{1,2,6}$, Laurent Bonello ${ }^{3,5, *}$

1- Aix Marseille Univ, INSERM, MMG, Marseille, France

2- APHM, CHU de la Timone, Laboratoire de Génétique Moléculaire, Marseille, France

3- MARS cardio, Mediterranean Association for research and studies in cardiology, Intensive care unit, Hospital Nord, Marseille, France

4- Cardiology department, CHU Timone, Marseille, France.

5- Aix Marseille Univ, INSERM, INRA, C2VN, Marseille, France

6- Aix Marseille Univ, Laboratoire de Chimie Analytique, Faculté de Pharmacie, Marseille, France

7- Service d'hématologie Biologique, Centre hospitalo-universitaire Timone, AssistancePublique Hôpitaux de Marseille, Marseille, France

8- CRB Assistance Publique - Hôpitaux de Marseille, HemoVasc (CRB AP-HM HemoVasc), Marseille, France

Word count: 3121

\section{*Corresponding author:}

Nathalie Bonello-Palot

Aix Marseille Univ, INSERM, MMG, Marseille, France

Department of Medical genetic,

Hôpital Timone enfants

264 rue Saint Pierre

13005 Marseille France

Phone: 01133491387787

Key words: acute coronary syndrome, lipodystrophy, genetic, premature 


\section{ABSTRACT}

Background and aims: Genetic partial Lipodystrophies are rare heterogeneous disorders characterized by abnormalities of fat distribution and associated metabolic complications including a predisposition for atherosclerotic cardiovascular disease. We hypothesized that the milder forms of these diseases might be underdiagnosed and might result in early acute coronary syndrome (ACS) as the first sign of the pathology.

Methods: We performed targeted sequencing on a panel of 8 genes involved in genetic lipodystrophy for 62 patients with premature ACS, and selected heterozygous missense variations with low frequency. To confirm those results, we analyzed a second independent group of 60 additional patients through Sanger sequencing, and compared to a control group of 120 healthy patients.

Results: In the first cohort, only PLIN1, exhibited variants in more than 1 patient. In PLIN1, 3 different variants were found in 6 patients. We then analyzed PLIN1 sequence in the second cohort with premature ACS and found 2 other patients. Altogether, 8 patients were carriers of 4 different mutations in PLIN1. The variant frequencies in the total cohort of 122 patients were compared to frequencies observed in a local control cohort and in 2 different public databases showing a significant difference between patient vs control group frequencies for two mutations out of 4 (c.245C $\left.>\mathrm{T} p=10^{-4} ; c .839 \mathrm{G}>\mathrm{A} p=0.014\right)$.

Discussion: This is the first study that identifies a high frequency of potential pathogenic mutations in PLIN1 related to early onset ACS. These findings could contribute to the prevention and care of precocious ACS in families carrying those mutations.

\section{INTRODUCTION}


Genetic lipodystrophies refer to a group of rare diseases characterized by the abnormal distribution of adipose tissue and metabolic anomalies including insulin resistance or type 2 diabetes and hypertriglyceridemia. These anomalies ultimately result in atherosclerosis and confer an increased risk of Acute Coronary Syndrome (ACS) [1][2]. The molecular causes of generalized partial lipodystrophies include a broad spectrum of proteins which can be classified into 2 groups: the first one gathers proteins which are key to adipocyte differentiation and are involved in premature aging syndrome; the second group includes proteins playing a role in the adipocyte lipid droplet formation and regulation [3].

Clinically, in genetic partial lipodystrophies, the fat loss is predominant on the limbs but can be present on the abdomen and chest in the most severe forms [4]. In parallel, adipose tissue accumulates on the face and neck and on organs that are not supposed to store fat, such as the liver and the heart. The severity of these syndromes varies, ranging from precocious onset right after puberty to later onset with an expression mimicking metabolic syndrome [5-7]. The majority of the cases reported so far are females, suggesting that male patients may be underdiagnosed since all described genes responsible for partial lipodystrophy are autosomal [8]. ACS is a major public health issue and the first cause of death worldwide [9]. A family history of coronary artery disease is a major risk factor for the disease but the genetic cause of the disease remains mostly undetermined except for familial hypercholesterolemia which only accounts for a limited number of patients with an early onset of ACS. Because genetic lipodystrophies are associated with ACS, we hypothesized that the milder forms of these diseases might be underdiagnosed and might result in early acute coronary syndrome (ACS) as the first sign of the pathology. 
To identify such gene alterations, we investigated a series of 62 individuals who experienced ACS, by the massive parallel sequencing of a panel of 8 genes involved in the most frequent genetic generalized or partial lipodystrophies: AGPAT2, BSCL2, CAV1, LMNA, PLIN1, PPARG, CAVIN1 and ZMPSTE24. Following this approach, we identified four very rare heterozygous mutations of PLIN1 encoding perilipin 1, a major component of the lipid droplet which regulates the release of free fatty acids from the droplet.

\section{MATERIALS AND METHODS}

\section{Patients}

We prospectively included 122 patients admitted to the cardiology departments of the North Hospital and La Timone Hospital in Marseille, for a first episode of ACS treated by percutaneous coronary intervention ( $\mathrm{PCl}$ ) and occurring before 55 years of age for women and before 50 years for men. ACS was defined according to the guidelines and includes both ST elevation and non-ST elevation ACS [10]. Only patients with at least one significant athero-thrombotic stenosis requiring $\mathrm{PCl}$ were included. We excluded patients whose ACS was due to non-atherosclerosis cause including trauma, dissection, septic embolus, toxic or coronary artery dissection.

The healthy control group was constituted of 120 individuals matched for gender and recruited in the same 2 centres as patients. These subjects were part of a larger cohort of 6154 individuals of French origin with no cardiovascular events before the age of 60, recruited as healthy controls [11]. 
The present study was approved by the institution review board and in accordance with the declaration of Helsinki. All patients accepted the study and gave written informed consent before inclusion.

\section{Clinical endpoint}

We recorded clinical ischemic and bleeding events during a 1-year follow-up period post-ACS (Table 1). Ischemic events are composed of major adverse cardiovascular events (MACE): cardiovascular death, myocardial infarction, urgent revascularization and stroke. Bleedings were assessed using the TIMI classification [12].

\section{Genetic analysis}

DNA was extracted from peripheral blood using standard procedures. DNAs were prepared and stored at the certified Biological Resource Center (CRB TAC component (NF S96-900 \& ISO 9001 v2015 Certification)). All DNAs belong to biological sample collections declared to the French Ministry of Health (declaration numbers DC-2008-429) whose use for research purposes was authorized by the French Ministry of Health (authorization AC-2011-1312 and AC-2017-2986).

\section{Next Generation Sequencing (NGS) study:}

The targeted regions correspond to the coding regions and intron-exon boundaries of the following genes: AGPAT2 (NM_006412), BSCL2 (NM_001122955), CAV1 (NM_001753), LMNA (NM_170707), PLIN1 (NM_002666), PPARG (NM_005037), CAVIN1 (NM_012232), and ZMPSTE24 (NM_005857). This panel focuses on genes associated with lipodystrophy and 
nucleopathy. The capture was performed with reagents from a custom design HaloPlex Target Enrichment kit (Agilent Technologies, USA), according to the HaloPlex Target Enrichment for lon Torrent Sequencing $\vee$ D4. Template preparation, emulsion PCR, and Ion Sphere Particles (ISP) enrichment were carried out using the lon $\mathrm{PI}^{\mathrm{TM}}$ Template OT2 $200 \mathrm{Kit}$ v2 on the Ion OneTouch ${ }^{\text {TM }} 2$ System (Thermo Fisher Scientific Inc. USA). The quality of the ISPs was assessed using a Qubit 2.0 Fluorometer, and the ISPs were loaded and sequenced on an Ion $\mathrm{PI}^{\mathrm{TM}}$ Chip Kit v2 using lon $\mathrm{PI}^{\mathrm{TM}}$ Sequencing 200 Kit v2 on the lon Proton ${ }^{\mathrm{TM}}$ Sequencer (Thermo Fisher Scientific Inc. USA). Raw data were first aligned with the provided software suite included with the Ion Proton system to generate BAM files. The coverage and sequencing depth analysis were computed using the BEDtools suite v2.17 and in-house scripts. Variants were identified using the Torrent Browser Variant caller (version 4.0.2), annotated and prioritized with the in-house VarAFT system that includes Annovar [13]. The deleterious effect of the sequence variation identified were analyzed by bioinformatics tools such as: MutationTaster (http://www.mutationtaster.org/) [14], SIFT (http://sift.bii.astar.edu.sg/) [15], PolyPhen-2 (http://genetics.bwh.harvard.edu/pph2/) [16] and UMD predictor (http://umd-predictor.eu/) [17].

All mutations in the PLIN1 gene were confirmed using Sanger sequencing according to standard procedures on ABI3500XL (Life Technologies, Carlsbad, C.A, U.S.A.). Mutations are numbered according to the GenBank reference sequence NM_002666 and the Human Genome Variation Society recommendations (http://varnomen.hgvs.org/).

\section{Statistical analysis}

Statistical analyses were performed using PASW Statistics version 17.0. Continuous variables are reported as means and standard deviation or as medians and range (according to their 
distribution), and categorical variables are reported as count and percentages. Univariate and multivariate analyses were performed using a logistic regression model to estimate the risk of ACS associated with the presence of PLIN1 mutated alleles. Odds ratios (OR) were estimated with a $95 \%$ confidence interval. The calibration of the logistic model was assessed using the Hosmer-Lemeshow goodness of fit test. A classification table was used to evaluate the predictive accuracy of the logistic regression model.

\section{RESULTS}

\section{Clinical data}

Our cohort was composed of a majority of male patients ( $81.6 \%)$. The mean age at the time of the first ACS was $43.6 \pm 7$ years old. Among cardiovascular risk factors, a family history of CAD was present in $37.5 \%(45 / 120)$ of patients, obesity in $67.8 \%(80 / 118)$, active smoking in $80.8 \%(97 / 120)$ and diabetes in $20.5 \%$ (24/117). Hypercholesterolemia and hypertriglyceridemia were present in $14 \%(16 / 111)$ and $35 \%(45 / 119)$ of the patients respectively. All clinical and laboratory data are summarized in Table 1.

Coronary angiography revealed multi-vessel disease in $67 \%(81 / 120)$ of patients. All patients received $\mathrm{PCl}$ of the culprit lesion with drug-eluting stents. $\mathrm{PCl}$ was successful in all patients.

Among the 122 patients included, a recurrent event of ACS was observed in $30.8 \%(37 / 120)$ over the one-year follow-up.

\section{Molecular findings}


NGS was first performed for a subgroup of 62 patients out of 122 included in the study, on a panel of 8 genes. We focused exclusively on rare heterozygous missense variations since in partial lipodystrophies, pathogenic variants are usually missense variants with dominant transmission mode. An allelic frequency cutoff to consider a variant as rare was established at 0.0015 in GnomAD database (https://gnomad.broadinstitute.org/).

Using the VarAFT software, we collected 68 variants in heterozygous condition, 10 were nonsynonymous and located on 5 out of the 8 genes. Among those, 4 variants in 2 genes had a frequency lower than the frequency cutoff set up at $0.15 \%$ in GnomAD. These 4 variants were not reported in ClinVar or PubMed as previously associated with a phenotype of lipodystrophy or any other pathogenic phenotype. The first variant, c.463G>A (p.Val155Ile), was located in CAV1 and was present in only one patient, the 3 others were located in one single gene, PLIN1, and were present in 6 patients. Four individuals shared the same variant: c.245C>T (p.Thr82lle) and two other patients carried a different variant in this gene: c.269T>C (p.Leu90Pro) and c.820C >T (p.Arg274Trp). All 3 variants were confirmed by Sanger sequencing (primer sequences in supplementary data).

We then tested a second sub-group of 60 patients by direct Sanger sequencing of the coding regions of PLIN1 and identified two other patients carrying a rare missense heterozygous mutation in PLIN1: the first patient was a carrier of the recurrent mutation previously identified in the first series: c.245C>T (p.Thr82lle), the second one carried a different mutation: c.839G>A (p.Arg280Trp).

Altogether, from the 122 patients included in the cohort, 8 ( 7 males) were carriers of a variant in PLIN1, 5 of whom carried the same variant and the remaining 3 carried 3 different variations. 
All variants are described as deleterious in at least two of the following prediction tools: Mutation Taster, Sift, Polyphen2 and UMD predictor. Severity prediction scores are shown in Table 2.

A transcripts study was performed for mutations c.245C >T (p.Thr821le), c.269T>C (p.Leu90Pro) and c.820C >T (p.Arg274Trp) because of the prediction by bioinformatics tools of a potential splicing alteration (http://www.umd.be/HSF3/HSF.shtml). These analyses did not confirm the prediction showing that roughly $50 \%$ of the transcripts carried the variation and that no abnormal transcript was produced.

\section{Allele frequencies in controls and in the studied cohort}

Allele frequencies and OR are summarized in Table 3. Univariate analysis confirmed the significantly higher prevalence of 2 of the PLIN1 mutations in patients with ACS compared to data frequency extracted from the GnomAD database: c. $245 \mathrm{C}>\mathrm{T}\left(p<10^{-4}\right)$ and $c .839 \mathrm{G}>\mathrm{A}$ $(p<0.014)$. For another mutation, a tendency was observed $(c .820 \mathrm{C}>\mathrm{T}: p=0.1)$.

As the ACS cohort was recruited in the south of France, we looked for a potential bias linked to the geographical origin of the patients. In order to compare the ACS cohort to a population with close geographical origins, we consulted another database gathering exome data from a reference control panel of individuals of French ancestry (FREX, https://www.france-genomique.org/). Only the recurrent c.245C $>\mathrm{T}$ mutation was found in this database with a frequency of 0.00795 i.e. comparable to the frequency reported for this mutation in GnomAD.

To investigate again a potential bias linked to the region of recruitment, we tested a local control cohort of 120 voluntary persons included in the same hospitals as the patients, by Sanger sequencing of PLIN1 coding regions. Out of the 120 controls, one male person was 
identified as a carrier of the recurrent c. $245 \mathrm{C}>\mathrm{T}$ mutation. The frequencies of the mutations were again significantly higher in the ACS cohort compared to controls and the risk of developing an ACS conferred by the presence of any of the 4 mutations in PLIN1 was significantly higher (OR, 8.2946, 95\% Cl: 1.0834; 372.9476, $p=0.035)$.

\section{Relationship between mutations and clinical profile or recurrence events}

When comparing patients with or without a mutation in PLIN1, we observed no significant difference regarding baseline clinical characteristics or biological parameters (Table 1 ). In particular, there was no difference in disease diffusion or rate of recurrent events ( $p$-values of respectively 0.6 and 1 ). We observed a tendency for the association of one risk factor, smoking, in the ACS group vs control group $(p=0.143)$.

\section{DISCUSSION}

In the present study, mutations frequency in PLIN1 is increased in patients who present with an ACS when compared to healthy volunteers without ACS or to 2 public exome aggregation databases. Four different missense mutations in PLIN1 gene were identified in 8 patients (Table 2). A mutated PLIN1 allele was more frequent in the ACS cohort than in the control group with an odd ratio of 8.3. Another missense variant was identified in CAV1 in one patient. Because previously described pathogenic mutations in CAV are nonsense mutations and only one patient was concerned, this variant was not further investigated [18] The significance of a family history of CAD for premature ACS (defined in this study as occurring before 50 years old for males and before 55 for females) has been recognized for more than 60 years [19]. The first identification of a molecular cause of precocious CAD was 
the characterization of mutations in the $L D L R$ gene responsible for familial hypercholesterolemia (FH) [20]. Although it was suggested that a network of proteins participated in atheroma plaque development such as proteins involved in lipid metabolism, the hereditability of premature CAD remains largely undetermined except for the very specific form due to $\mathrm{FH}[21,22]$. In fact numerous genome wide association studies (GWAS) have been conducted to identify loci associated with CAD. Up to now, more than 160 loci are described. Most of them are associated with common polymorphism and with modest effects on disease risk $[23,24]$.

Perilipin 1 is one of the 5 major members of the Perilipin family (perilipins 1 to 5 ) in humans. Perilipin 1 is involved in the control of neutral lipids stored in lipid droplets in cells [25]. In adipocytes at the basal state, it opposes triglyceride hydrolysis by preventing adipose triglyceride-lipase access to the lipid core of the droplet. After beta-adrenergic stimulation, perilipin 1 is phosphorylated by PKA on 5 specific sites and then promotes lipolysis by the hormone-sensitive lipase (HSL) or ATGL [25-27]. Two lipase-selective functional domains in perilipin 1 have been identified [28]. The phosphorylation of the 2 sites located in the Nterminal domain $\left(\operatorname{Ser}^{81}\right.$ and $\left.\operatorname{Ser}^{276}\right)$ seems to play a key role in the activation of lipolysis by HSL whereas those 3 in the C-terminal domain seem to involve lipolysis not linked to HSL and more specifically the lipolysis mediated by the adipose tissue triglyceride-lipase (ATGL) [28]. HSL and ATGL both induce hydrolysis of tri- and di-acyl glycerol, allowing the release of fatty acids and mono-acylglycerols. In our study, we report 4 mutations in close vicinity of the two phosphorylation sites of the N-terminal domain of perilipin $1 \operatorname{Ser}^{81}$ and $\operatorname{Ser}^{276}$ (Figure 1)[28]. These results fit the paradigm where free fatty acid mobilization and utilization improves prognosis. As specific examples, SGLT2 inhibitors enhance the mobilization and utilization of free fatty acids in many tissues and thus improve prognosis [29] while the 
described mutations in the perilipin gene near the phosphorylation sites may reduce the

mobilization of lipids stored in lipid droplets in cells, thus possibly worsening the prognosis.

Prediction tools for the phosphorylation site (http://gps.biocuckoo.org/online.php) showed that one of the mutations, p.Arg274Trp, abolishes the second phosphorylation site suggesting a possible pathological pathway through the alteration of the phosphorylation rate and an abnormal HSL activity leading to abnormal lipolysis. In the literature, 3 missense mutations of PLIN1 have been reported in 5 patients with autosomal dominant partial lipodystrophy $[30,31]$. These mutations were located at the C-terminal end of the protein and resulted in the expression of a truncated dysfunctional perilipin 1 lacking the 3 phosphorylation sites of the C-terminal part of the protein.

Beside adipocytes, perilipin 1 is also expressed in macrophages and vascular smooth muscle cells and is overexpressed in atheroma plaques [32,33], suggesting that it might play a role in the development of atherosclerosis by controlling the hydrolysis of esterified cholesterol in the above areas.

A study has been performed in obese mice KO for PLIN1 and showed the correction of obesity thanks to an increased metabolic rate [34]. Two other in vivo studies are contradictious as one concluded that expression of perilipin 1 may play an atheroprotective role [35] whereas the other showed that its deficiency resulted in atherosclerosis reduction [36].

In vitro, it was observed that in ruptured atheroma plaque, perilipin 1 expression was increased when compared to stable plaque, suggesting a potential role of this protein in plaque rupture [37]. The speculated mechanism is a reduced lipolysis when perilipin 1 is expressed resulting in increased lipid retention and thus plaque destabilization. In addition, perilipin 1 expression in macrophages favors an increase in lipid droplets formation and 
Triglycerides accumulation which favors conversion of macrophages into foam cells [38]. Up to now, there is no study reporting SNP in PLIN1 associated with an increasing risk of premature ACS ( https://www.gwascentral.org/ and https://www.ebi.ac.uk/gwas/).

Atheroma plaque rupture or erosion is the main event responsible for ACS in patients but the mechanism involved in these acute complications remains undetermined, preventing effective therapies from being developed. The identification of perilipin 1 as a potential key factor of premature ACS could help in defining new therapeutic strategies to prevent or stabilize athero-thrombotic processes. Moreover, the identification of mutations in genes strongly associated with premature ACS could be of major clinical interest for screening. Indeed, our findings, if confirmed, could enable the identification of patients with a high risk of developing CAD and trigger the introduction of primary prevention measures in these patients and their relatives, similarly to strategies previously adopted in familial hypercholesterolemia.

The limits of our study lie in the fact that the size of the cohort is limited. Investigations in a larger cohort with different geographical origins will be necessary to evaluate more precisely the prevalence of these mutations in patients with premature ACS. In addition, this study did not allow us to determine whether these mutations are associated with a higher risk of recurrent events. Functional analyses are ongoing to better delineate the mechanisms by which such mutations in PLIN1 impact the lipid droplet formation and may favor plaque destabilization.

CONFLICT OF INTEREST: none

FINANCIAL SUPPORT: The present study was funded by a research grant from MARS Cardio. 
AUTHOR CONTRIBUTIONS: CB, LB and NB took primary responsibility for the study; $C D, A B$,

FM, and AL performed experimental study; CB, PB and NB collected and analyzed the data,

AL performed statistical analysis. NB, CB and LB provided administrative support and access

to study material. All authors contributed to the critical revision and final approval of the

version to be published. The authors reported no potential conflict of interest.

ACKNOWLEDGEMENTS: We would like to thank the patients who participated in the study.

\section{REFERENCES}

[1] I. Hussain, N. Patni, A. Garg, Lipodystrophies, dyslipidaemias and atherosclerotic cardiovascular disease., Pathology (Phila.). 51 (2019) 202-212. https://doi.org/10.1016/j.pathol.2018.11.004.

[2] M.-C. Vantyghem, A.-S. Balavoine, C. Douillard, F. Defrance, L. Dieudonne, F. Mouton, C. Lemaire, N. Bertrand-Escouflaire, M.-F. Bourdelle-Hego, F. Devemy, A. Evrard, D. Gheerbrand, C. Girardot, S. Gumuche, C. Hober, H. Topolinski, B. Lamblin, B. Mycinski, A. Ryndak, W. Karrouz, E. Duvivier, E. Merlen, C. Cortet, J. Weill, D. Lacroix, J.-L. Wemeau, How to diagnose a lipodystrophy syndrome., Ann. Endocrinol. 73 (2012) 170-189. https://doi.org/10.1016/j.ando.2012.04.010.

[3] B. Akinci, R. Meral, E.A. Oral, Phenotypic and Genetic Characteristics of Lipodystrophy: Pathophysiology, Metabolic Abnormalities, and Comorbidities., Curr. Diab. Rep. 18 (2018) 143. https://doi.org/10.1007/s11892-018-1099-9.

[4] J. Capeau, J. Magre, M. Caron-Debarle, C. Lagathu, B. Antoine, V. Bereziat, O. Lascols, J.-P. Bastard, C. Vigouroux, Human lipodystrophies: genetic and acquired diseases of adipose tissue., Endocr. Dev. 19 (2010) 1-20. https://doi.org/10.1159/000316893.

[5] A. Decaudain, M.-C. Vantyghem, B. Guerci, A.-C. Hecart, M. Auclair, Y. Reznik, H. Narbonne, P.-H. Ducluzeau, B. Donadille, C. Lebbe, V. Bereziat, J. Capeau, O. Lascols, C. Vigouroux, New metabolic phenotypes in laminopathies: LMNA mutations in patients with severe metabolic syndrome., J. Clin. Endocrinol. Metab. 92 (2007) 4835-4844. https://doi.org/10.1210/jc.2007-0654.

[6] A. Dutour, P. Roll, B. Gaborit, S. Courrier, M.-C. Alessi, D.-A. Tregouet, F. Angelis, A. RobagliaSchlupp, N. Lesavre, P. Cau, N. Levy, C. Badens, P.-E. Morange, High prevalence of laminopathies among patients with metabolic syndrome., Hum. Mol. Genet. 20 (2011) 3779-3786. https://doi.org/10.1093/hmg/ddr294.

[7] I. Hussain, A. Garg, Lipodystrophy Syndromes., Endocrinol. Metab. Clin. North Am. 45 (2016) 783-797. https://doi.org/10.1016/j.ecl.2016.06.012. 
[8] A. Buffet, M. Lombes, P. Caron, [Genetics of congenital lipodystrophies]., Ann. Endocrinol. 76 (2015) S2-9. https://doi.org/10.1016/S0003-4266(16)30002-6.

[9] E.J. Benjamin, P. Muntner, A. Alonso, M.S. Bittencourt, C.W. Callaway, A.P. Carson, A.M. Chamberlain, A.R. Chang, S. Cheng, S.R. Das, F.N. Delling, L. Djousse, M.S.V. Elkind, J.F. Ferguson, M. Fornage, L.C. Jordan, S.S. Khan, B.M. Kissela, K.L. Knutson, T.W. Kwan, D.T. Lackland, T.T. Lewis, J.H. Lichtman, C.T. Longenecker, M.S. Loop, P.L. Lutsey, S.S. Martin, K. Matsushita, A.E. Moran, M.E. Mussolino, M. O'Flaherty, A. Pandey, A.M. Perak, W.D. Rosamond, G.A. Roth, U.K.A. Sampson, G.M. Satou, E.B. Schroeder, S.H. Shah, N.L. Spartano, A. Stokes, D.L. Tirschwell, C.W. Tsao, M.P. Turakhia, L.B. VanWagner, J.T. Wilkins, S.S. Wong, S.S. Virani, Heart Disease and Stroke Statistics-2019 Update: A Report From the American Heart Association., Circulation. 139 (2019) e56-e528. https://doi.org/10.1161/CIR.0000000000000659.

[10] R. Erbel, V. Aboyans, C. Boileau, E. Bossone, R. Di Bartolomeo, H. Eggebrecht, A. Evangelista, V. Falk, H. Frank, O. Gaemperli, M. Grabenwoger, A. Haverich, B. lung, A.J. Manolis, F. Meijboom, C.A. Nienaber, M. Roffi, H. Rousseau, U. Sechtem, P.A. Sirnes, R.S. von Allmen, C.J.M. Vrints, [2014 ESC Guidelines on the diagnosis and treatment of aortic diseases]., Kardiol. Pol. 72 (2014) 1169-1252. https://doi.org/10.5603/KP.2014.0225.

[11] E. Mazoyer, L. Ripoll, R. Gueguen, L. Tiret, J.-P. Collet, C.B. dit Sollier, J. Roussi, L. Drouet, Prevalence of factor $V$ Leiden and prothrombin G20210A mutation in a large French population selected for nonthrombotic history: geographical and age distribution., Blood Coagul. Fibrinolysis Int. J. Haemost. Thromb. 20 (2009) 503-510. https://doi.org/10.1097/MBC.0b013e32832f5d7a.

[12] R. Mehran, S. Pocock, E. Nikolsky, G.D. Dangas, T. Clayton, B.E. Claessen, A. Caixeta, F. Feit, S.V. Manoukian, H. White, M. Bertrand, E.M. Ohman, H. Parise, A.J. Lansky, A.M. Lincoff, G.W. Stone, Impact of bleeding on mortality after percutaneous coronary intervention results from a patient-level pooled analysis of the REPLACE-2 (randomized evaluation of PCl linking angiomax to reduced clinical events), ACUITY (acute catheterization and urgent intervention triage strategy), and HORIZONS-AMI (harmonizing outcomes with revascularization and stents in acute myocardial infarction) trials., JACC Cardiovasc. Interv. 4 (2011) 654-664. https://doi.org/10.1016/j.jcin.2011.02.011.

[13] J.-P. Desvignes, M. Bartoli, V. Delague, M. Krahn, M. Miltgen, C. Beroud, D. Salgado, VarAFT: a variant annotation and filtration system for human next generation sequencing data., Nucleic Acids Res. 46 (2018) W545-W553. https://doi.org/10.1093/nar/gky471.

[14] J.M. Schwarz, C. Rodelsperger, M. Schuelke, D. Seelow, MutationTaster evaluates diseasecausing potential of sequence alterations., Nat. Methods. 7 (2010) 575-576. https://doi.org/10.1038/nmeth0810-575.

[15] P. Kumar, S. Henikoff, P.C. Ng, Predicting the effects of coding non-synonymous variants on protein function using the SIFT algorithm., Nat. Protoc. 4 (2009) 1073-1081. https://doi.org/10.1038/nprot.2009.86.

[16] I.A. Adzhubei, S. Schmidt, L. Peshkin, V.E. Ramensky, A. Gerasimova, P. Bork, A.S. Kondrashov, S.R. Sunyaev, A method and server for predicting damaging missense mutations., Nat. Methods. 7 (2010) 248-249. https://doi.org/10.1038/nmeth0410-248.

[17] D. Salgado, J.-P. Desvignes, G. Rai, A. Blanchard, M. Miltgen, A. Pinard, N. Levy, G. Collod-Beroud, C. Beroud, UMD-Predictor: A High-Throughput Sequencing Compliant System for Pathogenicity Prediction of any Human cDNA Substitution., Hum. Mutat. 37 (2016) 439-446.

https://doi.org/10.1002/humu.22965. 
[18] A. Garg, M. Kircher, M. Del Campo, R.S. Amato, A.K. Agarwal, Whole exome sequencing identifies de novo heterozygous CAV1 mutations associated with a novel neonatal onset lipodystrophy syndrome., Am. J. Med. Genet. A. 167A (2015) 1796-1806.

https://doi.org/10.1002/ajmg.a.37115.

[19] P.D. White, Genes, the heart and destiny., N. Engl. J. Med. 256 (1957) 965-969.

https://doi.org/10.1056/NEJM195705232562101.

[20] M.S. Brown, J.L. Goldstein, A receptor-mediated pathway for cholesterol homeostasis., Science. 232 (1986) 34-47.

[21] R. McPherson, A. Tybjaerg-Hansen, Genetics of Coronary Artery Disease., Circ. Res. 118 (2016) 564-578. https://doi.org/10.1161/CIRCRESAHA.115.306566.

[22] P.G. Joseph, G. Pare, S. Asma, J.C. Engert, S. Yusuf, S.S. Anand, Impact of a Genetic Risk Score on Myocardial Infarction Risk Across Different Ethnic Populations., Can. J. Cardiol. 32 (2016) 14401446. https://doi.org/10.1016/j.cjca.2016.05.014.

[23] M. Nikpay, A. Goel, H.-H. Won, L.M. Hall, C. Willenborg, S. Kanoni, D. Saleheen, T. Kyriakou, C.P. Nelson, J.C. Hopewell, T.R. Webb, L. Zeng, A. Dehghan, M. Alver, S.M. Armasu, K. Auro, A. Bjonnes, D.I. Chasman, S. Chen, I. Ford, N. Franceschini, C. Gieger, C. Grace, S. Gustafsson, J. Huang, S.-J. Hwang, Y.K. Kim, M.E. Kleber, K.W. Lau, X. Lu, Y. Lu, L.-P. Lyytikainen, E. Mihailov, A.C. Morrison, N. Pervjakova, L. Qu, L.M. Rose, E. Salfati, R. Saxena, M. Scholz, A.V. Smith, E. Tikkanen, A. Uitterlinden, X. Yang, W. Zhang, W. Zhao, M. de Andrade, P.S. de Vries, N.R. van Zuydam, S.S. Anand, L. Bertram, F. Beutner, G. Dedoussis, P. Frossard, D. Gauguier, A.H. Goodall, O. Gottesman, M. Haber, B.-G. Han, J. Huang, S. Jalilzadeh, T. Kessler, I.R. Konig, L. Lannfelt, W. Lieb, L. Lind, C.M. Lindgren, M.-L. Lokki, P.K. Magnusson, N.H. Mallick, N. Mehra, T. Meitinger, F.U.-R. Memon, A.P. Morris, M.S. Nieminen, N.L. Pedersen, A. Peters, L.S. Rallidis, A. Rasheed, M. Samuel, S.H. Shah, J. Sinisalo, K.E. Stirrups, S. Trompet, L. Wang, K.S. Zaman, D. Ardissino, E. Boerwinkle, I.B. Borecki, E.P. Bottinger, J.E. Buring, J.C. Chambers, R. Collins, L.A. Cupples, J. Danesh, I. Demuth, R. Elosua, S.E. Epstein, T. Esko, M.F. Feitosa, O.H. Franco, M.G. Franzosi, C.B. Granger, D. Gu, V. Gudnason, A.S. Hall, A. Hamsten, T.B. Harris, S.L. Hazen, C. Hengstenberg, A. Hofman, E. Ingelsson, C. Iribarren, J.W. Jukema, P.J. Karhunen, B.-J. Kim, J.S. Kooner, I.J. Kullo, T. Lehtimaki, R.J.F. Loos, O. Melander, A. Metspalu, W. Marz, C.N. Palmer, M. Perola, T. Quertermous, D.J. Rader, P.M. Ridker, S. Ripatti, R. Roberts, V. Salomaa, D.K. Sanghera, S.M. Schwartz, U. Seedorf, A.F. Stewart, D.J. Stott, J. Thiery, P.A. Zalloua, C.J. O'Donnell, M.P. Reilly, T.L. Assimes, J.R. Thompson, J. Erdmann, R. Clarke, H. Watkins, S. Kathiresan, R. McPherson, P. Deloukas, H. Schunkert, N.J. Samani, M. Farrall, A comprehensive 1,000 Genomes-based genome-wide association meta-analysis of coronary artery disease., Nat. Genet. 47 (2015) 11211130. https://doi.org/10.1038/ng.3396.

[24] P. van der Harst, N. Verweij, Identification of 64 Novel Genetic Loci Provides an Expanded View on the Genetic Architecture of Coronary Artery Disease., Circ. Res. 122 (2018) 433-443. https://doi.org/10.1161/CIRCRESAHA.117.312086.

[25] D.L. Brasaemle, Thematic review series: adipocyte biology. The perilipin family of structural lipid droplet proteins: stabilization of lipid droplets and control of lipolysis., J. Lipid Res. 48 (2007) 2547-2559. https://doi.org/10.1194/jlr.R700014-JLR200.

[26] M.J. Watt, G.R. Steinberg, Regulation and function of triacylglycerol lipases in cellular metabolism., Biochem. J. 414 (2008) 313-325. https://doi.org/10.1042/BJ20080305. 
[27] D.L. Brasaemle, V. Subramanian, A. Garcia, A. Marcinkiewicz, A. Rothenberg, Perilipin A and the control of triacylglycerol metabolism., Mol. Cell. Biochem. 326 (2009) 15-21.

https://doi.org/10.1007/s11010-008-9998-8.

[28] H.H. Zhang, S.C. Souza, K.V. Muliro, F.B. Kraemer, M.S. Obin, A.S. Greenberg, Lipase-selective functional domains of perilipin A differentially regulate constitutive and protein kinase Astimulated lipolysis., J. Biol. Chem. 278 (2003) 51535-51542.

https://doi.org/10.1074/jbc.M309591200.

[29] C.G. Santos-Gallego, J.A. Requena-Ibanez, R. San Antonio, K. Ishikawa, S. Watanabe, B. Picatoste, E. Flores, A. Garcia-Ropero, J. Sanz, R.J. Hajjar, V. Fuster, J.J. Badimon, Empagliflozin Ameliorates Adverse Left Ventricular Remodeling in Nondiabetic Heart Failure by Enhancing Myocardial Energetics., J. Am. Coll. Cardiol. 73 (2019) 1931-1944. https://doi.org/10.1016/j.jacc.2019.01.056.

[30] S. Gandotra, C. Le Dour, W. Bottomley, P. Cervera, P. Giral, Y. Reznik, G. Charpentier, M. Auclair, M. Delepine, I. Barroso, R.K. Semple, M. Lathrop, O. Lascols, J. Capeau, S. O’Rahilly, J. Magre, D.B. Savage, C. Vigouroux, Perilipin deficiency and autosomal dominant partial lipodystrophy., N. Engl. J. Med. 364 (2011) 740-748. https://doi.org/10.1056/NEJMoa1007487.

[31] K. Kozusko, V.H.M. Tsang, W. Bottomley, Y.-H. Cho, S. Gandotra, M. Mimmack, K. Lim, I. Isaac, S. Patel, V. Saudek, S. O'Rahilly, S. Srinivasan, J.R. Greenfield, I. Barroso, L.V. Campbell, D.B. Savage, Clinical and molecular characterization of a novel PLIN1 frameshift mutation identified in patients with familial partial lipodystrophy., Diabetes. 64 (2015) 299-310.

https://doi.org/10.2337/db14-0104.

[32] F. Forcheron, L. Legedz, G. Chinetti, P. Feugier, D. Letexier, G. Bricca, M. Beylot, Genes of cholesterol metabolism in human atheroma: overexpression of perilipin and genes promoting cholesterol storage and repression of ABCA1 expression., Arterioscler. Thromb. Vasc. Biol. 25 (2005) 1711-1717. https://doi.org/10.1161/01.ATV.0000174123.19103.52.

[33] O. Hofnagel, I. Buers, M. Schnoor, S. Lorkowski, H. Robenek, Expression of perilipin isoforms in cell types involved in atherogenesis., Atherosclerosis. 190 (2007) 14-5; author reply 16-17. https://doi.org/10.1016/j.atherosclerosis.2006.06.010.

[34] J. Martinez-Botas, J.B. Anderson, D. Tessier, A. Lapillonne, B.H. Chang, M.J. Quast, D. Gorenstein, K.H. Chen, L. Chan, Absence of perilipin results in leanness and reverses obesity in Lepr(db/db) mice., Nat. Genet. 26 (2000) 474-479. https://doi.org/10.1038/82630.

[35] D. Langlois, F. Forcheron, J.-Y. Li, P. del Carmine, S. Neggazi, M. Beylot, Increased atherosclerosis in mice deficient in perilipin1., Lipids Health Dis. 10 (2011) 169. https://doi.org/10.1186/1476511X-10-169.

[36] X. Zhao, M. Gao, J. He, L. Zou, Y. Lyu, L. Zhang, B. Geng, G. Liu, G. Xu, Perilipin1 deficiency in whole body or bone marrow-derived cells attenuates lesions in atherosclerosis-prone mice., PloS One. 10 (2015) e0123738. https://doi.org/10.1371/journal.pone.0123738.

[37] B.C. Faber, K.B. Cleutjens, R.L. Niessen, P.L. Aarts, W. Boon, A.S. Greenberg, P.J. Kitslaar, J.H. Tordoir, M.J. Daemen, Identification of genes potentially involved in rupture of human atherosclerotic plaques., Circ. Res. 89 (2001) 547-554. 
[38] J. Persson, E. Degerman, J. Nilsson, M.W. Lindholm, Perilipin and adipophilin expression in lipid loaded macrophages., Biochem. Biophys. Res. Commun. 363 (2007) 1020-1026. https://doi.org/10.1016/j.bbrc.2007.09.074.

\section{Legends:}

Figure 1: Schematic views of (A) PLIN1 gene with mutations reported in this work (black boxes: coding exons). (B) perilipin 1 protein with the different phosphorylation.

\section{Tables:}

Table 1: Baseline characteristics of the 120 patients with SCA. (2 out of the 122 patients had no clinical data available).

Table 2: Bioinformatics software prediction and allelic frequencies in GnomAD: http://gnomad.broadinstitute.org/ for the 4 mutations identified in PLIN1.

Table 3: Risks associated with the presence of the mutations (control: GnomAD and cohort: 122 patients with Precocious ACS) 